\title{
The German adaptation of the Cambridge pulmonary hypertension outcome review (CAMPHOR)
}

\author{
Katharina Cima', James Twiss ${ }^{2}$, Rudolf Speich ${ }^{3 *}$, Stephen P McKenna ${ }^{2}$, Ekkehard Grünig ${ }^{4}$, Christian M Kähler ${ }^{1}$, \\ Nicola Ehlken ${ }^{4}$, Ursula Treder ${ }^{3}$, Sigrid R Crawford ${ }^{2}$, Lars $C$ Huber $^{3}$ and Silvia Ulrich ${ }^{3}$
}

\begin{abstract}
Background: Individuals with precapillary pulmonary hypertension $(\mathrm{PH})$ experience severely impaired quality of life. A disease-specific outcome measure for PH, the Cambridge Pulmonary Hypertension Outcome Review (CAMPHOR) was developed and validated in the UK and subsequently adapted for use in additional countries. The aim of this study was to translate and assess the reliability and validity of the CAMPHOR for German-speaking populations.

Methods: Three main adaptation stages involved; translation (employing bilingual and lay panels), cognitive debriefing interviews with patients and validation (assessment of the adaptation's psychometric properties). The psychometric evaluation included 107 patients with precapillary PH (60 females; age mean (standard deviation) 60 (15) years) from 3 centres in Austria, Germany and Switzerland.

Results: No major problems were found with the translation process with most items easily rendered into acceptable German. Participants in the cognitive debriefing interviews found the questionnaires relevant, comprehensive and easy to complete. Psychometric analyses showed that the adaptation was successful. The three CAMPHOR scales (symptoms, activity limitations and quality of life) had excellent test-retest reliability correlations (Symptoms $=0.91$; Activity limitations $=0.91 ; \mathrm{QoL}=0.90)$ and internal consistency (Symptoms =0.94; Activity limitations =0.93; QoL =0.94). Predicted correlations with the Nottingham Health Profile provided evidence of the construct validity of the CAMPHOR scales. The CAMPHOR adaptation also showed known group validity in its ability to distinguish between participants based on perceived general health, perceived disease severity, oxygen use and NYHA classification.
\end{abstract}

Conclusions: The CAMPHOR has been shown to be valid and reliable in the German population and is recommend for use in clinical practice.

Keywords: Pulmonary hypertension, Pulmonary arterial hypertension, Chronic thromboembolic pulmonary hypertension, Quality of life, Patient reported outcome, German adaptation

\section{Introduction}

Precapillary pulmonary hypertension $(\mathrm{PH})$ consists of the WHO clinical classes 1 and 4, i.e. pulmonary arterial hypertension $(\mathrm{PAH})$ and chronic thromboembolic $\mathrm{PH}$ (CTEPH). Despite many new therapeutic options (with the exception of patients with operable CTEPH) life expectancy is still dramatically shortened [1-3]. Hence, the search for new therapies is on-going, and multiple trials

\footnotetext{
* Correspondence: rudolf.speich@usz.ch

${ }^{3}$ Pulmonary Hypertension Program, University Hospital, Zurich, Switzerland Full list of author information is available at the end of the article
}

are underway or being planned. One of the main problems of planning such large trials is the absence of an ideal endpoint [4]. Invasive haemodynamic parameters are considered to represent hard endpoints, which are optimal for phase II trials. However, it is not feasible to perform these measurements repeatedly in everyday clinical practice. Most trials now rely on the 6-minute walking distance (6MWD) as the primary endpoint. However, this test has many flaws including disagreement about the normal values, the quality with which it is conducted, high standard deviation of distances walked 
and large minimally important difference of over 40 meters [5]. In reality, exercise testing does not provide an accurate reflection of how patients really feel.

As a consequence, quality of life (QoL) has emerged as a potentially important endpoint. Most clinical studies to date have used generic patient-reported outcome measures such as the SF-36 [6-9], the EuroQol $[9,10]$ or the Nottingham Health Profile [11]. However, generic instruments generally have a low responsiveness, particularly with $\mathrm{PH}$ patients [12]. For instance, the minimally important difference of the SF-36 domains range between 13 and 25 points on a 100-point scale [12]. This implies that scores have to improve by up to 25 points before the change is noticeable by patients. Some trials have applied a modified version of the Minnesota Living with Heart Failure (MLWHF) questionnaire [13,14]. Although this has been shown to have a reasonable performance $[15,16]$ it was not designed for patients with $\mathrm{PH}$.

Given the impact of $\mathrm{PH}$ on morbidity, comprehensive disease-specific measures that directly address $\mathrm{PH}$ characteristics are needed. The Cambridge Pulmonary Hypertension Outcome Review (CAMPHOR) was designed as a disease-specific measure to assess both healthrelated QoL (symptoms and activity limitations) and QoL in patients diagnosed with PH [17]. It is an evaluation tool designed for use in clinical trials and clinical practice. The present paper describes the translation and validation of the CAMPHOR for use in German speaking countries. A successful adaptation will provide a valid and reliable outcome measure for use in $\mathrm{PH}$ clinical practice and clinical trials at German speaking centres.

\section{Methods}

The adaptation of the CAMPHOR questionnaire was conducted in the three German-speaking countries; Austria, Germany and Switzerland. The process consisted of three main stages; translation (by means of bilingual and lay panels), cognitive debriefing interviews with patients to determine face and content validity and validation by means of a clinic visit and postal survey. Ethics committee approval was obtained from each participating centre and written informed consent was obtained from all participants.

\section{Step 1: Translation process}

The bilingual translation panel involved a group of 2 Austrian, 3 German and 4 Swiss participants 7 females and 2 males with a median age of 47 and a range of 30 to 62 years) with good competence in both English and German who had the latter as their primary language. They were asked to consider the UK CAMPHOR instructions and items with the following requirements in mind; capturing the same concepts as the UK English version and producing a comprehensible and acceptable formulation of the concepts. Each item was discussed until agreement was reached. Where consensus could not be reached alternative versions of the item were taken forward for consideration by the lay panel.

A separate lay translation panel consisted of 1 Austrian, 2 German and 3 Swiss non-bilingual participants (3 females and 3 males; median age 27 ranging from 18 to 76 years). The purpose of this second panel was to ensure that the wording of items was appropriate for future respondents with average educational achievement. Participants were presented with the translations made by the bilingual panel and asked to comment on these in terms of comprehension and acceptability. In particular, they were asked to decide whether phrasing and language were acceptable or whether these should be changed to make the items more 'natural' while maintaining their original meaning. Where necessary they were also asked to choose between alternative translations that the bilingual panel had produced.

\section{Step 2: Cognitive debriefing interviews}

Cognitive debriefing interviews were conducted with 4 $\mathrm{PH}$ patients from each country (Table 1). Eight of the interviewees had idiopathic pulmonary arterial hypertension (IPAH), 3 chronic thromboembolic pulmonary hypertension (CTEPH) and 1 had $\mathrm{PH}$ associated with scleroderma. The purpose of these interviews was to test the applicability, comprehension, relevance and comprehensiveness of the new scales with relevant patients. In the interviews, which were conducted face-to-face and semi-structured, the respondents were asked to complete the questionnaire in the presence of an interviewer and then to answer specific questions about the measure. Respondents were also asked whether any aspects of their experience of $\mathrm{PH}$ had been omitted.

\section{Step 3: Validation}

To validate the German version of the CAMPHOR, 107 $\mathrm{PH}$ patients from the three participating centres were recruited (Tables 1 and 2). During a visit to the outpatient clinic questions about demography (sex, age, marital status, occupation) and current condition (time since diagnosis, duration of symptoms, oxygen use and perceived general health) were asked. During the visit a $6 \mathrm{MWT}$ also was performed according to current guidelines [18]. This measures the distance a patient can walk quickly on a flat, hard surface in 6 minutes. It is intended to indicate functional capacity. Its reliability has been shown to be good in a number of different diseases [19-21]. The measure has also been shown to correlate with a number of $\mathrm{PH}$ related outcomes [22,23].

NYHA functional class was determined at the outpatient visit (Class 1, no functional limitation; Class 2, 
Table 1 Demographic information

\begin{tabular}{|c|c|c|}
\hline & $\begin{array}{l}\text { Cognitive debriefing } \\
\text { interview panel } \\
(n=12)\end{array}$ & $\begin{array}{l}\text { Validation sample } \\
\quad(n=107)\end{array}$ \\
\hline \multicolumn{3}{|l|}{ Gender } \\
\hline Male (\%) & $3(25.0)$ & $46(43.4)$ \\
\hline Female (\%) & $9(75.0)$ & $60(56.6)$ \\
\hline Missing & 0 & 1 \\
\hline \multicolumn{3}{|l|}{ Age (years) } \\
\hline Mean (SD) & $60.2(17.9)$ & $60.3(15.1)$ \\
\hline Range & $22-80$ & $22-88$ \\
\hline Missing & 0 & 0 \\
\hline \multicolumn{3}{|l|}{ Nationality } \\
\hline Swiss (\%) & $4(33.3)$ & 39 (36.4) \\
\hline Austrian (\%) & $4(33.3)$ & $34(31.8)$ \\
\hline German (\%) & $4(33.3)$ & $34(31.8)$ \\
\hline Missing & 0 & 0 \\
\hline \multicolumn{3}{|l|}{ Marital status } \\
\hline Married/living as married (\%) & $7(58.3)$ & $68(64.2)$ \\
\hline Living alone (\%) & $5(41.7)$ & $38(35.8)$ \\
\hline Missing & 0 & 1 \\
\hline \multicolumn{3}{|l|}{ Employment status } \\
\hline Working (\%) & $3(25.0)$ & $21(19.8)$ \\
\hline Not working (\%) & $9(75.0)$ & $85(80.2)$ \\
\hline Missing & 0 & 1 \\
\hline
\end{tabular}

slight functional limitation; Class 3 , marked functional limitation; Class 4, inability to perform functions without symptoms) [24].

Patients also completed the Nottingham Health Profile (NHP; [25]).

The CAMPHOR was then administered on two occasions by mail approximately two weeks apart.

\section{Statistical analyses}

Data are presented as means and standard deviations (SD) for illustrative purposes. Non-parametric statistical tests were used throughout the analyses due to the ordinal nature of the measures employed. All statistical tests were two-tailed with a $P$ value of $<.05$ indicating statistical significance. Internal consistency of the CAMPHOR adaptations was evaluated by determining Cronbach's alpha coefficients. The relatedness of individual items to the overall score was also assessed using the corrected item-total correlation coefficients. Test-retest reliability (patient-specific agreement between the two repeated administrations) was examined using Spearman's rank correlations. Construct validity was assessed with the NHP as the comparator instrument.
Table 2 Validation sample; disease information $(n=107)$

\begin{tabular}{|c|c|}
\hline Cause of $\mathrm{PH}$ & \\
\hline Idiopathic PAH (\%) & $47(45.2)$ \\
\hline Associated PAH (\%) & $24(21.2)$ \\
\hline CTEPH (\%) & $36(33.6)$ \\
\hline Missing & 0 \\
\hline \multicolumn{2}{|l|}{ Duration of PH (years) } \\
\hline Mean (SD) & $4.0(4.5)$ \\
\hline Range & $0.2-25.0$ \\
\hline Missing & 6 \\
\hline \multicolumn{2}{|c|}{ Hospital admission in last year due to $\mathrm{PH}$} \\
\hline Yes (\%) & $4(3.8)$ \\
\hline No $(\%)$ & $101(96.2)$ \\
\hline Missing & 2 \\
\hline \multicolumn{2}{|l|}{ Oxygen } \\
\hline Yes (\%) & $40(37.7)$ \\
\hline No (\%) & $66(62.3)$ \\
\hline Missing & 1 \\
\hline \multicolumn{2}{|l|}{ NYHA Classification } \\
\hline I (\%) & $3(2.8)$ \\
\hline \| (\%) & $42(39.3)$ \\
\hline III (\%) & $56(52.3)$ \\
\hline IV (\%) & $6(5.6)$ \\
\hline Missing & 0 \\
\hline \multicolumn{2}{|l|}{6 Min Walk Test (metres) } \\
\hline Mean (SD) & $447.9(112.7)$ \\
\hline Range & $180-660$ \\
\hline Missing & 8 \\
\hline \multicolumn{2}{|l|}{ Perceived general health } \\
\hline Very good/Good (\%) & $65(62.5)$ \\
\hline Fair (\%) & $28(26.9)$ \\
\hline Very poor/ Poor (\%) & 11(10.6) \\
\hline Missing & 3 \\
\hline \multicolumn{2}{|l|}{ Perceived severity of $\mathrm{PH}$} \\
\hline No symptoms (\%) & $2(1.9)$ \\
\hline Mild (\%) & $23(22.3)$ \\
\hline Moderate (\%) & $55(53.4)$ \\
\hline Very \& Quite severe (\%) & $23(22.3)$ \\
\hline Missing & 12 \\
\hline
\end{tabular}

Known-group validity (ability to distinguish between groups of patients who differed according to some known factor) was tested for:

- Perceived general health (very good/good; fair; poor/ very poor)

- Perceived PH severity (No symptoms/mild; Moderate; Quite severe/very severe) 
- Oxygen use (yes / no)

- NYHA class (NYHA I and II versus NYHA III and IV)

\section{Outcome measures CAMPHOR}

The CAMPHOR was originally developed and validated in the United Kingdom [17]. It has subsequently been adapted for use in the US [26], Canada (French and English) [27], Australia / New Zealand [28] and Sweden. It consists of a 25-item symptoms scale (scored 0-25), a 15-item functioning scale (scored 0-30) and a 25-item QoL scale (scored 0-25). For all scales, a low score indicates a better status. All language versions have been shown to have good internal consistency, reproducibility and validity [26-28].

\section{Nottingham Health Profile}

The NHP is a 38-item measure of perceived distress that has been widely used in health research [25]. It consists of six sections that assess; energy level, pain, emotional reactions, sleep, social isolation and physical mobility. All sections are scored 0 to 100 with a low score indicating good health status.

The NHPD is a 24-item unidimensional scale of impairment embedded in the NHP [29].

\section{Results}

\section{Translation}

No major difficulties were experienced during the translation process and most items in the questionnaire were translated without difficulty. Agreement was generally reached with little panel discussion. However, a small number of phrases required more extensive discussion. For example, "glücklich" was chosen instead of "zufrieden" for "happy" since the latter was considered to be closer to "satisfied" than "happy". "Mein Zustand belastet mich" was preferred to "Mein Zustand nimmt mich mit" for "It gets me down" because the former was thought to represent the burden of the disease better. "Zur Zeit" was favoured over "zum jetzigen Zeitpunkt" for "at the moment", as the latter was believed to be more accurate.

\section{Cognitive debriefing interviews}

The CAMPHOR was completed in a median of 15 (range 7 to 25) minutes. Based on their responses participants found the questionnaire to be clear, unambiguous, comprehensive and easy to complete. Only minor difficulties were reported. For example, one patient had difficulty understanding one of the items and another thought that a different item was not relevant. None of the patients judged the questionnaire to be inappropriate or difficult to answer. Three patients thought that an additional item should be added to the questionnaire.
Each suggested a different item and none were relevant to the content of the scales. No changes were required to the questionnaire as a result of the cognitive debriefing interviews. However, despite the instructions, only two respondents checked that they had answered all questions after completing the measure. Consequently, the instructions were highlighted in an attempt to overcome this oversight.

\section{Validation}

One-hundred and seven participants were recruited at Time 1. At Time 2, 97 of these (90.7\%) completed and returned the questionnaires.

\section{Sample demographics}

Participant details are shown in Table 1. Individual country sample sizes were insufficient to permit assessment of the national psychometric properties separately and the samples were merged for the analysis. Disease information for the sample is shown in Table 2.

\section{Questionnaire descriptive scores}

The missing response rate at the item level on both the CAMPHOR and NHP varied between 2 and $3 \%$.

CAMPHOR scores at Time 1 are shown in Table 3. The scores for the CAMPHOR were relatively low suggesting that the sample had relatively mild $\mathrm{PH}$. Floor effects ( $>10 \%$ of patients scoring minimum) were evident for the QoL scale. This reflects the mild nature of the sample.

\section{Internal consistency and reproducibility}

Internal consistency and test-retest reliability (reproducibility) are shown in Table 4. Reproducibility was above the required 0.85 level for all three scales. Internal consistency (Cronbach's alpha) coefficients for the three scales were above the minimum required 0.7 indicating adequate inter-relatedness of items in each scale. The coefficients were above 0.9 for all CAMPHOR scales suggesting possible redundancy of items. The corrected item-total correlation coefficients (CITCC) were examined for all three scales to determine if there were any redundant items (items outside the $0.2-0.8$ range). None of the items had CITCC's above 0.8. In addition, the deletion of any one item would not have decreased the Cronbach's alpha value significantly.

\section{Convergent validity}

Table 5 shows correlations between the CAMPHOR, NHP and the 6MWT at Time 1 . The symptoms scale showed strongest correlations with the emotional reactions, energy level and physical mobility sections of the NHP. It is known that PH has a close relation to these outcomes. The activity limitations scale most closely 
Table 3 Questionnaire descriptive scores Time $1(n=107)$

\begin{tabular}{|c|c|c|c|c|c|c|}
\hline & Mean (SD) & Median & IQR & Range & $\%$ scoring minimum & $\%$ scoring maximum \\
\hline \multicolumn{7}{|l|}{ CAMPHOR } \\
\hline Symptoms & $7.4(6.5)$ & 5.5 & $2-13$ & $0-25$ & 8.4 & 0.9 \\
\hline Activity limitations & $8.7(6.3)$ & 8.0 & $3-13$ & $0-29$ & 6.5 & 0 \\
\hline QoL & $5.1(6.0)$ & 3.0 & $1-7$ & $0-24$ & 21.5 & 0 \\
\hline \multicolumn{7}{|l|}{ NHP } \\
\hline Energy level & $38.6(38.3)$ & 33.3 & $0-66.7$ & $0-100$ & 37.4 & 18.7 \\
\hline Pain & $10.6(19.8)$ & 0.0 & $0-12.5$ & $0-100$ & 60.7 & 0.9 \\
\hline Emotional reactions & $13.0(18.1)$ & 0.0 & $0-22.2$ & $0-78$ & 48.6 & 0 \\
\hline Sleep & $24.5(29.1)$ & 20.0 & $0-40$ & $0-100$ & 42.1 & 2.8 \\
\hline Social isolation & $5.2(13.7)$ & 0.0 & 0 & $0-80$ & 80.4 & 0 \\
\hline Physical mobility & $22.3(21.0)$ & 12.5 & $0-37.5$ & $0-100$ & 29.0 & 0.9 \\
\hline NHPD & $3.4(3.6)$ & 2.0 & $0-6$ & $0-14$ & 28.0 & 0 \\
\hline
\end{tabular}

related to physical mobility and energy level. Again this would be expected as the activity limitations scale assesses physical mobility and energy level is also closely related to mobility. For the same reason the 6MWT had the highest correlation with the activity limitations scale of the CAMPHOR. QoL was clearly influenced by all issues covered by the NHP but less so by pain and social isolation.

\section{Association of CAMPHOR scores with demographic factors}

There were no significant differences in mean CAMPHOR scores related to gender with the exception of the Activity limitations scale where females scored higher than males (means $=9.3$ and 7.8 respectively, $\mathrm{p}<.05$ ). Older individuals (above median age) scored higher on the Symptoms scale than younger respondents (means = 5.9 and 9.1 respectively, $\mathrm{p}<.05)$ and Activity limitations scale $($ means $=6.7$ and 10.9 respectively, $\mathrm{p}<0.001$ ). There were no differences in CAMPHOR scale scores related to duration of $\mathrm{PH}$

\section{Known group validity}

Known groups validity results are shown in Table 6. All three CAMPHOR scales were able to discriminate between patients based on their perceived general health and severity of $\mathrm{PH}$. Individuals with worse general health and worse PH had higher scores for the Symptoms, Activity limitations and QoL scales. All three CAMPHOR scales were able to distinguish between participants

Table 4 Internal consistency and reproducibility of the CAMPHOR scales adaptations $(n=107)$

\begin{tabular}{lccc}
\hline & Symptoms & Activity limitations & QoL \\
\hline Internal consistency & .94 & .93 & .94 \\
Test-retest reliability & .91 & .91 & .90 \\
\hline
\end{tabular}

based on whether or not participants received oxygen for their $\mathrm{PH}$.

Figure 1 shows CAMPHOR scores by NYHA classification. The figure shows that the CAMPHOR was able to discriminate well between patients. Due to the small number of patients in classes I and IV statistical analyses compared respondents in NYHA groups I and II combined with participants in groups III and IV combined. Individuals in groups NHYA III \& IV had higher CAMPHOR scores than those in NHYA I and II (Symptoms $\mathrm{p}<.001$; Activity limitations $\mathrm{p}<.001$; QoL $\mathrm{p}<.05$ ).

\section{Discussion}

The results showed that the adaptation of the CAMPHOR for use with German speaking participants was successful. Few problems were encountered during the translation process. All participants in the cognitive debriefing panel reported that the measure was easy to complete and that it covered important aspects of their experience of $\mathrm{PH}$.

All scales in the CAMPHOR had good internal consistency and reproducibility. The CAMPHOR showed expected levels of association with the different

Table 5 Convergent validity CAMPHOR scales and NHP sections $(n=107)$

\begin{tabular}{lccc}
\hline & Symptoms & Activity limitations & QoL \\
\hline NHP-Energy level & .82 & .66 & .71 \\
NHP-Pain & .45 & .56 & .54 \\
NHP-Emotional reactions & .74 & .59 & .72 \\
NHP-Sleep & .50 & .39 & .51 \\
NHP-Social isolation & .39 & .32 & .38 \\
NHP-Physical mobility & .74 & .76 & .70 \\
NHP-D & .81 & .66 & .72 \\
6 Minute Walk Test (meters) & -.43 & -.56 & -.41 \\
\hline All correlations were significant at $\mathrm{p}<.01$. & &
\end{tabular}


Table 6 CAMPHOR scale scores by disease factors $(n=100-102)$

\begin{tabular}{|c|c|c|c|c|c|c|c|c|c|}
\hline & \multicolumn{3}{|c|}{ Symptoms } & \multicolumn{3}{|c|}{ Activity limitations } & \multicolumn{3}{|c|}{ QoL } \\
\hline & $n$ & Mean & $(\mathrm{SD})$ & $n$ & Mean & (SD) & $n$ & Mean & $(\mathrm{SD})$ \\
\hline \multicolumn{10}{|c|}{ Perceived general health } \\
\hline Very good/good & 64 & 4.4 & $(4.3)$ & 63 & 6.1 & $(5.2)$ & 64 & 2.7 & (3.8) \\
\hline Fair & 26 & 10.7 & $(5.8)$ & 28 & 10.9 & $(5.3)$ & 25 & 7.6 & $(6.8)$ \\
\hline Poor/very poor & 11 & 17.6 & $(3.5)$ & 11 & 17.1 & $(4.9)$ & 11 & 13.3 & $(5.3)$ \\
\hline $\mathrm{p}$ & & \multicolumn{2}{|c|}{$<.001$} & \multicolumn{3}{|c|}{$<.001$} & & \multicolumn{2}{|c|}{$<.001$} \\
\hline \multicolumn{10}{|c|}{ Perceived severity of $\mathrm{PH}$} \\
\hline No symptoms / mild & 25 & 3.7 & $(3.4)$ & 25 & 5.3 & $(4.3)$ & 25 & 2.3 & $(2.7)$ \\
\hline Moderate & 53 & 5.9 & $(5.4)$ & 54 & 7.4 & $(5.5)$ & 53 & 3.9 & $(5.4)$ \\
\hline Quite / very severe & 23 & 15.2 & $(4.6)$ & 23 & 15.1 & $(5.3)$ & 22 & 11.1 & $(6.1)$ \\
\hline $\mathrm{p}$ & & \multicolumn{2}{|c|}{$<.001$} & \multicolumn{3}{|c|}{$<.001$} & & \multicolumn{2}{|c|}{$<.001$} \\
\hline \multicolumn{10}{|l|}{ Oxygen use } \\
\hline Yes & 38 & 9.8 & $(6.8)$ & 37 & $11.6(6.7)$ & & 37 & 7.3 & $(6.5)$ \\
\hline No & 63 & 5.9 & $(5.7)$ & 65 & $7.0(5.5)$ & & 63 & 3.6 & $(5.0)$ \\
\hline$p$ & & \multicolumn{2}{|c|}{.003} & \multicolumn{3}{|c|}{$<.001$} & & \multicolumn{2}{|c|}{.001} \\
\hline
\end{tabular}

NHP sections. Further evidence of the validity of the German CAMPHOR was shown by its ability to distinguish between groups known to differ by perceived disease severity, general health and oxygen use. Importantly, clinical validity was also demonstrated; CAMPHOR scores were moderately related to the 6MWT and were able to distinguish between NYHA classifications. On the basis of these findings clinicians working in the three German-speaking nations can have confidence in CAMPHOR scale scores.

One of the strengths of the study is that it tested the CAMPHOR in 3 German-speaking countries. In all these countries written German is the same modern Standard German known as High German (Hochdeutsch). Most non-German researchers may not consider the differences between the German speaking

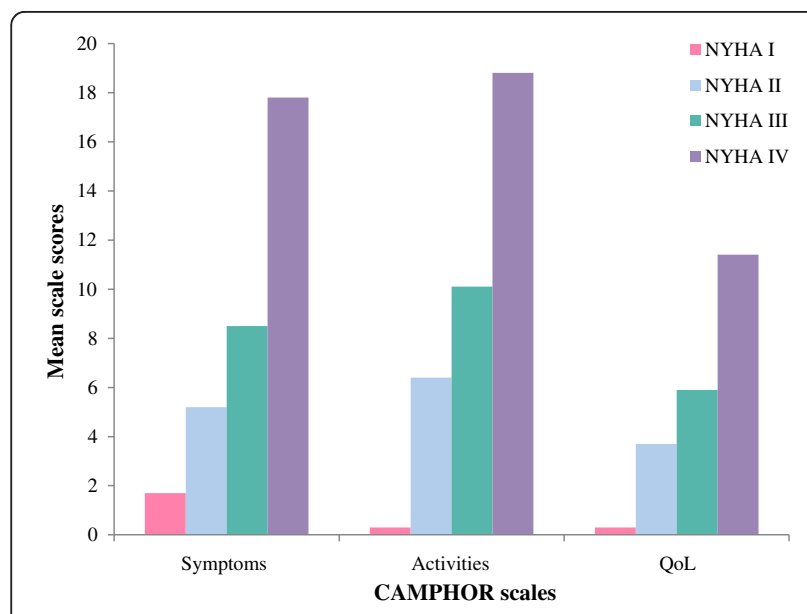

Figure 1 Mean CAMPHOR scales scores by NHYA classifications. nationalities and assume that an adaptation in one country will be suitable for all German speakers. However, the language used in the CAMPHOR is, intentionally, as informal as possible and it is possible that this could have led to differences in wording in the different countries. Variations between the German dialects are considerable and often only the neighbouring dialects are mutually intelligible. Low German, most Upper German and even some Central German dialects when spoken in their purest form are not intelligible to people who only know standard German. The German dialects of South Tyrol have been influenced by local Romance languages with many words borrowed from Italian. Furthermore, there is no standard Swiss German. Valais German differs markedly from Bernese German. Hence, adapting the CAMPHOR in relatively central cities in the three countries should guarantee a broad understandability.

The sample included in this study appeared to be less severe than those commonly included in clinical trials and in the UK validation survey. However, this study was designed to test the performance of the German CAMPHOR rather than to report on the impact of $\mathrm{PH}$ on QoL. Future studies can be undertaken to relate $\mathrm{PH}$ variables to QoL.

Increasingly, health authorities are conducting economic evaluations in health care. High-cost orphan diseases like $\mathrm{PH}$ are prone to careful scrutinisation. The preferred methodology is cost utility analysis (CUA) whereby the benefits of health care interventions are measured according to quality adjusted life years (QALYs). Due to their lack of sensitivity and relevance, the commonly used generic preference based measures of health status may be inappropriate for some specific 
clinical conditions such as $\mathrm{PH}$. The CAMPHOR Utility Index embedded in the CAMPHOR QoL scale permits derivation of $\mathrm{PH}$-specific utility scores [30]. In contrast to traditional outcomes, such as NYHA functional class, 6MWD and generic QoL instruments, it has been shown to be valid and responsive to change [31]. Further studies testing the use of the CAMPHOR utility index with German speaking PH patients would be beneficial.

In conclusion, the current study shows that the German translation of the CAMPHOR is a valid and reliable instrument for assessment of health-related QoL and QoL in patients with precapillary $\mathrm{PH}$. Its use in clinical practice can be recommended.

\section{Competing interests}

None of the authors have any competing interests.

\section{Authors information}

The CAMPHOR is a copyrighted instrument that is available free of licensing fees for use by clinicians and researchers in non-commercial studies. A small administrative fee is charged for such use. Readers interested in using the CAMPHOR should contact Stephen McKenna on smckenna@galen-research. com or www.galen-research.com

\section{Authors' contributions}

KC contributed to data acquisition, data analysis and drafting of the article. JT and SPM, contributed to study design, data collection, data analysis and interpretation of results. RS contributed to study design, data collection, data analysis, and drafting of the manuscript. EG, CMK, NE, UT contributed to data acquisition. SRC contributed to data analysis and interpretation of results. $\mathrm{LCH}$ contributed to data analysis and drafting of the manuscript. SU contributed to study design and data acquisition. All authors were involved with the critical revision of the manuscript.

\section{Author details}

${ }^{1}$ Department für Innere Medizin, Schwerpunkt Pneumologie,

Universitätsklinik, Innsbruck, Austria. ${ }^{2}$ Galen Research Ltd, Manchester, UK. ${ }^{3}$ Pulmonary Hypertension Program, University Hospital, Zurich, Switzerland. ${ }^{4}$ Thoraxklinik, Universitätsklinikum, Heidelberg, Germany.

Received: 4 May 2012 Accepted: 21 August 2012

Published: 13 September 2012

\section{References}

1. Humbert M, Sitbon $O$, Yaïci A, Montani D, O'Callaghan DS, Jaïs X, Parent F, Savale L, Natali D, Günther S, Chaouat A, Chabot F, Cordier JF, Habib G, Gressin V, Jing ZC, Souza R, Simonneau G, French Pulmonary Arterial Hypertension Network: Survival in incident and prevalent cohorts of patients with pulmonary arterial hypertension. Eur Respir J 2010, 36:549-55.

2. Shapiro S, Traiger GL, Turner M, McGoon MD, Wason P, Barst RJ: Sex differences in the diagnosis, treatment, and outcome of patients with pulmonary arterial hypertension enrolled in the registry to evaluate early and long-term PAH disease management (REVEAL). Chest 2011, 141(2):363-373.

3. Condliffe R, Kiely DG, Gibbs JS, Corris PA, Peacock AJ, Jenkins DP, Hodgkins D, Goldsmith K, Hughes RJ, Sheares K, Tsui SS, Armstrong IJ, Torpy C, Crackett R, Carlin CM, Das C, Coghlan JG, Pepke-Zaba J: Improved outcomes in medically and surgically treated chronic thromboembolic pulmonary hypertension. Am J Respir Crit Care Med 2008, 177:1122-1127.

4. McLaughlin W, Badesch DB, Delcroix M, Fleming TR, Gaine SP, Galiè N, Gibbs JS, Kim NH, Oudiz RJ, Peacock A, Provencher S, Sitbon O, Tapson VF, Seeger W: End points and clinical trial design in pulmonary arterial hypertension. J Am Coll Cardiol 2009, 54:S97-S107.

5. Benza RL, Miller DP, Gomberg-Maitland M, Frantz RP, Foreman AJ, Coffey CS, Frost A, Barst RJ, Badesch DB, Elliott CG, Liou TG, McGoon MD: Predicting survival in pulmonary arterial hypertension: insights from the Registry to
Evaluate Early and Long-Term Pulmonary Arterial Hypertension Disease Management (REVEAL). Circulation 2010, 122:164-172.

6. Galiè N, Olschewski H, Oudiz RJ, Torres F, Frost A, Ghofrani HA, Badesch DB, McGoon MD, McLaughlin W, Roecker EB, Gerber MJ, Dufton C, Wiens BL, Rubin $\sqcup$ : Ambrisentan for the treatment of pulmonary arterial hypertension: results of the ambrisentan in pulmonary arterial hypertension, randomized, double-blind, placebo-controlled, multicenter, efficacy (ARIES) study 1 and 2. Circulation 2008, 117:3010-3019.

7. Jaïs X, D'Armini AM, Jansa P, Torbicki A, Delcroix M, Ghofrani HA, Hoeper MM, Lang IM, Mayer E, Pepke-Zaba J, Perchenet L, Morganti A, Simonneau $G$, Rubin $\sqcup$ : Bosentan for treatment of inoperable chronic thromboembolic pulmonary hypertension: BENEFiT (Bosentan Effects in iNopErable Forms of chronlc Thromboembolic pulmonary hypertension), a randomized, placebo-controlled trial. J Am Coll Cardiol 2008, 52:2127-2134.

8. Simonneau G, Rubin LJ, Galiè N, Barst RJ, Fleming TR, Frost AE, Engel PJ, Kramer MR, Burgess G, Collings L, Cossons N, Sitbon O, Badesch DB, PACES Study Group: Addition of sildenafil to long-term intravenous epoprostenol therapy in patients with pulmonary arterial hypertension: a randomized trial. Ann Intern Med 2008, 149:521-530.

9. Galiè N, Brundage BH, Ghofrani HA, Oudiz RJ, Simonneau G, Safdar Z, Shapiro S, White RJ, Chan M, Beardsworth A, Frumkin L, Barst RJ: Tadalafil therapy for pulmonary arterial hypertension. Circulation 2009, 119:2894-2903.

10. Olschewski H, Simonneau G, Galiè N, Higenbottam T, Naeije R, Rubin LJ, Nikkho S, Speich R, Hoeper MM, Behr J, Winkler J, Sitbon O, Popov W, Ghofrani HA, Manes A, Kiely DG, Ewert R, Meyer A, Corris PA, Delcroix M, Gomez-Sanchez M, Siedentop H, Seeger W: Inhaled iloprost for severe pulmonary hypertension. N Engl J Med 2002, 347:322-329.

11. Barst RJ, Rubin LJ, Long WA, McGoon MD, Rich S, Badesch DB, Groves BM, Tapson VF, Bourge RC, Brundage BH, Koerner SK, Langleben D, Keller CA, Murali S, Uretsky BF, Clayton LM, Jöbsis MM, Blackburn SD, Shortino D, Crow JW, for the Primary Pulmonary Hypertension Study Group: A comparison of continuous intravenous epoprostenol (prostacyclin) with conventional therapy for primary pulmonary hypertension. The Primary Pulmonary Hypertension Study Group. N Engl J Med 1996, 334:296-302.

12. Gilbert C, Brown MC, Cappelleri JC, Carlsson M, McKenna SP: Estimating a minimally important difference in pulmonary arterial hypertension following treatment with sildenafil. Chest 2009, 135:137-142.

13. McLaughlin W, Benza RL, Rubin LJ, Channick RN, Voswinckel R, Tapson VF, Robbins IM, Olschewski H, Rubenfire M, Seeger W: Addition of inhaled treprostinil to oral therapy for pulmonary arterial hypertension: a randomized controlled clinical trial. J Am Coll Cardiol 2010, 55:1915-1922.

14. Simonneau G, Barst RJ, Galie N, Naeije R, Rich S, Bourge RC, Keogh A, Oudiz R, Frost A, Blackburn SD, Crow JW, Rubin LJ: Continuous subcutaneous infusion of treprostinil, a prostacyclin analogue, in patients with pulmonary arterial hypertension: a double-blind, randomized, placebo-controlled trial. Am J Respir Crit Care Med 2002, 165:800-804.

15. Cenedese E, Speich R, Dorschner L, Ulrich S, Maggiorini M, Jenni R, Fischler M: Measurement of Quality of Life in pulmonary hypertension and its significance. Eur Respir J 2006, 28:808-815.

16. Chen H, De Marco T, Kobashigawa EA, Katz PP, Chang WW, Blanc PD: Comparison of cardiac and pulmonary-specific quality-of-life measures in pulmonary arterial hypertension. Eur Respir J 2011, 38:608-616.

17. McKenna SP, Doughty N, Meads DM, Doward LC, Pepke-Zaba J: The Cambridge Pulmonary Hypertension Outcome Review (CAMPHOR): A measure of health-related quality of life and quality of life for patients with pulmonary hypertension. Qual Life Res 2006, 15:103-115.

18. ATS: Statement:guidelines for the six-minute walk test. Am J Respir Crit Care Med 2002, 166:111-117.

19. Wilsher M, Good N, Hopkins R, Young P, Milne D, Gibson A, Suppiah R, Ly J, Doughty $R$, Dalbeth $N$ : The six-minute walk test using forehead oximetry is reliable in the assessment of scleroderma lung disease. Respirology 2012, 17(4):647-652. May.

20. Goldman MD, Marrie RA, Cohen JA: Evaluation of the six-minute walk in multiple sclerosis subjects and healthy controls. Mult Scler 2008, 14(3):383-390. Apr.

21. Sciurba F, Criner GJ, Lee SM, Mohsenifar Z, Shade D, Slivka W, Wise RA: National Emphysema Treatment Trial Research Group. Six-minute walk 
distance in chronic obstructive pulmonary disease: reproducibility and effect of walking course layout and length. Am J Respir Crit Care Med 2003, 167:1522-1527.

22. Gomberg-Maitland M, Huo D, Benza RL, McLaughlin W, Tapson VF, Barst RJ: Creation of a model comparing 6-minute walk test to metabolic equivalent in evaluating treatment effects in pulmonary arterial hypertension. J Heart Lung Transplant 2007, 26:732-738.

23. Oudiz RJ, Barst RJ, Hansen JE, Sun XG, Garofano R, Wu X, Wasserman K, et al: Cardiopulmonary exercise testing and six-minute walk correlations in pulmonary arterial hypertension. Am J Cardiol 2006, 97:123-126.

24. The Criteria Committee of the New York Heart Association: Nomenclature and Criteria for Diagnosis of Diseases of the Heart and Great Vessels. 9th edition. Boston, Mass: Little, Brown \& Co; 1994:253-256.

25. Hunt SM, McEwen J: McKenna SP. Measuring Health Status London: Croom Helm; 1986.

26. Gomberg-Maitland M, Thenappan T, Rizvi K, Chandra S, Meads DM, McKenna SP: United States validation of the Cambridge Pulmonary Hypertension Outcome Review (CAMPHOR). J Heart Lung Transplant 2008, 27:124-130

27. Coffin D, Duval K, Martel S, Granton J, Lefebvre MC, Meads DM, Twiss J, McKenna SP: Adaptation of the Cambridge Pulmonary Hypertension Outcome Review (CAMPHOR) into French-Canadian and EnglishCanadian. Can Respir J 2008, 15:77-83.

28. Ganderton L, Jenkins S, McKenna SP, Gain K, Fowler R, Twiss J, Gabbay E: Validation of the Cambridge Pulmonary Hypertension Outcome Review (CAMPHOR) for the Australian and New Zealand population. Respirology 2011, 16:1235-1240.

29. McKenna SP, Hunt SM, Tennant A: The development of a patientcompleted index of distress from the Nottingham Health Profile: A new measure for use in cost-utility studies. Br J Med Econ 1993, 6:13-24.

30. McKenna SP, Ratcliffe J, Meads DM, Brazier JE: Development and validation of a preference based measure derived from the Cambridge Pulmonary Hypertension Outcome Review (CAMPHOR) for use in cost utility analyses. Health Qual Life Outcomes 2008, 6:65

31. Meads DM, McKenna SP, Doughty N, Das C, Gin-Sing W, Langley J, PepkeZaba J: The responsiveness and validity of the CAMPHOR Utility Index. Eur Respir J 2008, 32:1513-1519.

doi:10.1186/1477-7525-10-110

Cite this article as: Cima et al:: The German adaptation of the Cambridge pulmonary hypertension outcome review (CAMPHOR). Health and Quality of Life Outcomes 2012 10:110.

\section{Submit your next manuscript to BioMed Central and take full advantage of:}

- Convenient online submission

- Thorough peer review

- No space constraints or color figure charges

- Immediate publication on acceptance

- Inclusion in PubMed, CAS, Scopus and Google Scholar

- Research which is freely available for redistribution 